\title{
A Clinical Study of Hypothyroidism Associated With Type - 2 Diabetes Mellitus
}

\author{
Prakash Ajmera ${ }^{\circledR 1}$, P Sailaja ${ }^{2}$, P Raghu Ramulu ${ }^{3}$ \\ ${ }^{1}$ Assistant Professor, Department of General Medicine, Bhaskar Medical College \& Bhaskar General Hospital, Bhaskar Nagar, Moinabad, Hyderabad, India, ${ }^{2}$ Assistant \\ professor, Department of Gynaecology, Bhaskar Medical College \& Bhaskar General Hospital, Bhaskar Nagar, Moinabad, Hyderabad, India, ${ }^{3}$ Professor and Head, \\ Department of General Medicine, Bhaskar Medical College \& Bhaskar General Hospital, Bhaskar Nagar, Moinabad, Hyderabad, India.
}

\section{Abstract}

Background: Thyroid disorders are common in the general population and the incidence of type 2 diabetes mellitus is also rapidly increasing day by day. The objective is to determine the age and sex prevalence, pattern of presentation and management of patients suffering from hypothyroidism associated with type-2 diabetes mellitus. Subjects and Methods: Design: The study was an observational study of 20 types 2 diabetics attending the Department of Medicine (outpatient/inpatient). Duration: 1 year i.e. from December 2004 - December 2005. Setting: Out-patient department. Participants:20 patients with both Diabetes Mellitus type 2 and Hypothyroidism. Patients with known diabetes attending OPD were considered. Data were collected using a standardized case report form. Results: The majority of the patients had got diagnosed with hypothyroidism and diabetes within a span of 0 to 5 years, followed by 6 to 9 years span with 4 patients and 3 patients within the span of 10 to 14 years and 2 patients in the span of 15 to 19 years. Only 1 patient was diagnosed with both in a span of 20- to 24 years and one patient in 25 to 29 years. Conclusion: Annual Screening is mandatory in all hypothyroid patients for the early detection and treatment of diabetes mellitus, thereby to prevent and/or postpone the complications of diabetes, and all diabetes mellitus patients to undergo thyroid function screening (TFT) yearly for the early detection of thyroid dysfunction and thereby reducing the morbidity and mortality.

Keywords: Hypothyroidism, Diabetes Mellitus

Corresponding Author: P Raghu Ramulu, Professor and Head, Department of General Medicine, Bhaskar Medical College \& Bhaskar General Hospital, Bhaskar Nagar, Moinabad, Hyderabad, India.

E-mail: drpraghuramulu364@gmail.com

\section{Introduction}

Thyroid disorders are common in the general population and are reported to be $6.6 \%$ and the incidence of type 2 diabetes mellitus is also rapidly increasing day by day. Epidemiological studies in India indicate that there has been an increase in diabetic patients from $8.2 \%$ to $11.6 \%$ in the urban areas and from $1.5 \%$ to $2.75 \%$ in rural areas. India is going to be the world capital of diabetes in near future. One out of every 6 diabetic lives in India.

The association between hypothyroidism and diabetes has long been recognized through the reported prevalence of thyroid dysfunction varied between studies. ${ }^{[1]}$

The increased association of diabetes and thyroid disorder whether a co-existing disease or causal relation between these two disorders has not well been studied. ${ }^{[2]}$ Hence this small study is undertaken to have some insight into the association of diabetes and hypothyroidism.

\section{Hypothyroidism}

The thyroid gland produces two related hormones, thyroxine (T4) and triiodothyronine (T3). These hormones play a critical role in cell differentiation during development and help to maintain thermogenic metabolic homeostasis in the adult. Thyroid hormone act through nuclear hormone receptor to modulate gene expression. Disorders of the thyroid gland result primarily from autoimmune processes that either stimulates the overproduction of thyroid hormones (Thyrotoxicosis) or cause glandular destruction and underproduction of thyroid hormones (Hypothyroidism).

\section{Diabetes Mellitus}

The worldwide prevalence of diabetes mellitus has risen dramatically over the past two decades; it is projected that individuals with DM will continue to increase in the near future. The number of Although the prevalence of both type 1 and type $2 \mathrm{DM}$ is increasing worldwide, the prevalence of 
type DM is expected to rise more rapidly in the near future because of increasing obesity and reduced activity levels. The prevalence of type $2 \mathrm{DM}$ and its harbinger, impaired glucose tolerance (IGT), its highest in certain pacific islands, intermediate in countries such as India and the United States and relatively low in Russia and China. ${ }^{[3]}$ The variability is likely due to both genetic and environmental factors. There is also considerable variation in DM prevalence among the different ethnic populations within a given country Type 2 diabetes is rapidly emerging, as a major public health problem. There are an estimated 25-30 million persons with diabetes in India. ${ }^{[4]}$ This number could raise to 57 million and increase of $148 \%$ by $2025 .{ }^{[5]}$ Infect, by the year 2010 , India will surpass the world as regards the number of diabetic patients. The high prevalence is reported particularly from urban areas. High genetic predisposition changing lifestyle with the associated and high imbalanced intake of dietary fats seems to play a role. In India type 2 diabetes seems to occur a decade earlier (30-40 years) compared to the west. The paucity of dramatic symptoms, poor health awareness and the Prevailing socioeconomic conditions delay diagnosis.

\section{Aims of the Study}

- The Age and Sex prevalence,

- The pattern of presentation,

- The other associated disorders and

- The management aspects of hypothyroidism associated with type 2 diabetes mellitus patients.

\section{Objective}

To determine the age and sex prevalence, pattern of presentation and management of patients suffering from hypothyroidism associated with type-2 diabetes mellitus.

\section{Subjects and Methods}

The present study was conducted on 20 patients who attended the outpatient clinic to M.G.M. Hospital, Warangal from December 2004 to December 2005.

Inclusion Criteria: The patients who have both hypothyroidism and type 2 diabetes mellitus were included.

\section{Method of Study}

The patients who have both hypothyroidism and Type 2 diabetes mellitus were studied as outlined in the following Proforma.

\section{Results}

The majority of the patients belonged to the age group of 30 to 39 years when diagnosed with hypothyroidism were 6 patients,
The least belonging to the age group of 60 to 69 years group with 1 patient.

The majority of the patients who belonged to the age group of 30 to 39 years and 50 to 59 years group were diagnosed with type 2 diabetes. The least belonged to the age group of 40 to 49 years and 60 to 69 years with 3 patients in each age group.

The majority of the patients had got diagnosed with hypothyroidism and diabetes within a span of 0 to 5 years, followed by a 6 to 9 years span with 4 patients and 3 patients within the span of 10 to 14 years and 2 patients in the span of 15 to 19 years. Only 1 patient was diagnosed with both in a span of 20 to 24 years and one patient in 25 to 29 years.

\section{Discussion}

The present study enrolled 20 patients who have both hypothyroidism type- 2 diabetes mellitus. Sex: Out of these 20 patients females were 15 and males were 5 (F: $\mathrm{M}$ ratio is $3: 1$ ). So this, the association is 3 times more common in females than males. According to the study of Perused. et al. ${ }^{[6]}$ female to male ratio was 2.31 . Age: The mean age at diagnosis of hypothyroidism is $39.95 \pm 9.3$ \{Range (23- 63 Years). A High Incidence of $30 \%(6 / 20)$ was seen in the age group of 30-39 years. A low incidence of 5\% (1/20) was seen in the age group of 60-69 years. The mean age at diagnosis of diabetes is 48.15 \pm 10.135 ears [Range 33-69 years]. A high incidence of $70 \%$ [14/201 was observed in the 4th decade [7/20] and 6th decade [7/20]. The incidence of diabetes mellitus in hypothyroid patients is showing a bite pa pattern. The reason is not well explained anyhow it is a significant finding. The mean age of these 20 patients is $54.10 \pm 9.4$ years [ 30.71 years]. The peak incidence of this association was observed in the 6th decade in $45 \%$ of patients [9/20]. The low incidence of this association was observed in the $5^{\text {th }}$ decade 5\% [1/20]. Perros et. al. ${ }^{[6]}$ reported a high incidence of hypothyroidism in Type2 Diabetes in the 7th and 8th decades.

The onset of two diseases is not simultaneously noted in any single majority of the cases i.e. 95\% (19 out of 20) patients presented with the case. In hypothyroidism first, only in $5 \%$ (I patient) type 2 diabetes mellitus was noted first. If the time interval is taken into consideration between the onsets of two disorders maximum number of patients with hypothyroidism developed Type-2 diabetes mellitus within 5 years of onset of hypothyroidism. The maximum period taken is 25 years. The mean duration between diagnosis of hypothyroidism and Type 2 diabetes is $8.85 \pm 5.52$. The delay in the diagnosis of diabetes mellitus may be possible in these patients because hypothyroidism with raised TSH levels may mask the symptoms of diabetes mellitus and it may increase insulin sensitivity. Analysis of thyroid hormones showed that TSH levels were increased in almost all patients i.e., 95\% (19 out of 20 patients). T3 levels and T4 levels were below 


\begin{tabular}{|l|lllll|}
\hline Table 1: Master chart depicting age onset of diabetes and hypothyroidism and age difference between both \\
\hline I.P/ O.P no. & Sex & Age & $\begin{array}{l}\text { Age at diagnosis of Hypothy- } \\
\text { roidism }\end{array}$ & $\begin{array}{l}\text { Age at diagnosis of } \\
\text { Diabetes }\end{array}$ & $\begin{array}{l}\text { The duration between } \\
\text { these 2 disorders }\end{array}$ \\
\hline 6005 & F & 55 & 25 & 35 & 10 \\
\hline 7042 & F & 38 & 33 & 34 & 1 \\
\hline 7085 & F & 39 & 31 & 35 & 4 \\
\hline 9842 & M & 50 & 25 & 43 & 18 \\
\hline 10047 & F & 48 & 45 & 47 & 2 \\
\hline 11052 & F & 70 & 63 & 68 & 5 \\
\hline 12127 & F & 56 & 35 & 53 & 18 \\
\hline 14143 & F & 50 & 30 & 35 & 5 \\
\hline 15726 & F & 71 & 51 & 59 & 8 \\
\hline 12756 & F & 53 & 38 & 33 & 5 \\
\hline 27237 & F & 65 & 50 & 63 & 13 \\
\hline 32756 & F & 70 & 50 & 69 & 19 \\
\hline 33729 & F & 64 & 50 & 55 & 3 \\
\hline 34123 & F & 55 & 53 & 52 & 10 \\
\hline 47527 & M & 38 & 23 & 33 & 6 \\
\hline 56734 & F & 39 & 31 & 37 & 20 \\
\hline 62135 & F & 57 & 35 & 55 & 18 \\
\hline 72134 & M & 70 & 40 & 58 & 6 \\
\hline 82175 & M & 59 & 44 & 50 & 1 \\
\hline 79639 & M & 50 & 47 & 49 & \\
\hline
\end{tabular}

normal majority of patients ( 13 below normal in $55 \%$ and T4 below normal $75 \%$ ) in spite of taking an optimum dose of thyroid replacement therapy. It is reviewed in the literature that subclinical hypothyroidism is a common feature of diabetes mellitus and T3 levels are selectively increased in relation to hyperglycemia. ${ }^{[7-10]}$

In our study selected hypothyroidism patients with type 2 Diabetes mellitus and who are on thyroid replacement therapy, still, show low levels of T4 in spite of optimum dose. Most probably this group of people may require higher doses of hormone replacement therapy. An interesting finding is noted in the family history of these patients that 5 patients had a family history of hypothyroidism but none had a history of diabetes. On the other hand, two patients having a family history of Diabetes mellitus had no history of hypothyroidism in their family members. It is concluded that the common hereditary factor for both diseases does not exist. Anyhowpolyglandular autoimmune diseases (PGA) were not studied in this considering high-risk factors, in this group of patients, it is interestingly noted that hypertension is more common i.e., in 55\% (11 patients). Complications like coronary artery disease are seen in the hypertension-associated group i.e., $45 \%$ ( 4 out of 11 patients) and $20 \%$ (4 out of 20 patients) in this study group. Whereas stroke CVA / T1A is seen in $22 \%$ ( 2 out of 11 patients) of those who are also hypertensive group and $10 \%$ ( 2 out of 20 patients) in this study group. It is considered that more morbidity either in the form of CAD and CVA is noted when hypertension is added as a risk factor. The common sharing risk factor is hyperlipidemia i.e., present in $80 \%$ com ( 16 out of 20 patients). Hence it is suggested that hyperlipidemia is having a stronger relation to complications in these patients. On review of lipid profile pattern total cholesterol is raised more than $250 \mathrm{mg}$ in 5 patients and target level of LDL below $100 \mathrm{mg}$ is not seen in any patients even though on treatment. Hence lipid control may be a difficult problem in these subsets of patients. Any have control of hypothyroidism resulting in better glycemic and lipid control is not studied well and it is beyond the scope of this work. Interestingly one patient has presented with recurrent hypokalemic periodic paralysis. The correlation is not well explained in the literature, may be related to potassium channelopathy. All patients are on thyroxine replacement therapy. 16 patients are on oral hypoglycemic agents, 2 patients are on insulin + Oral hypoglycemic agents, 1 patient is only on a diabetic diet and 11 patients who have hypertension are on ACE inhibitors. HBA1c. Levels were estimated only in three patients, all of them have $p$ 


\begin{tabular}{|c|c|c|c|c|c|}
\hline I.P / O.Pno. & T3 (mg/dl) & T4( $(\mu \mathrm{g} / \mathrm{dl})$ & TSH $(\mu$ IU $/ \mathbf{m l})$ & FBS (mg/dl) & PLBS (mg/dl) \\
\hline 6005 & 66.5 & 7.8 & 0.71 & 120 & 206 \\
\hline 7042 & 35 & 1.8 & 16.2 & 152 & 178 \\
\hline 7085 & 80 & 5.4 & 14.2 & 210 & 296 \\
\hline 9842 & 30 & 3.5 & 20.5 & 110 & 150 \\
\hline 10047 & 45 & 2.8 & 16.2 & 14.3 & 260 \\
\hline 11052 & 59 & 0.8 & 10.4 & 11.6 & 194 \\
\hline 12127 & 55 & 2.8 & 8.6 & 220 & 320 \\
\hline 14143 & 85 & 5.8 & 10.2 & 166 & 210 \\
\hline 15726 & 45 & 1.8 & 10.6 & 112 & 187 \\
\hline 12756 & 105 & 6.4 & 6.2 & 112 & 210 \\
\hline 27237 & 25 & 0.8 & 17.4 & 130 & 240 \\
\hline 32756 & 30 & 4.0 & 20.0 & 157 & 248 \\
\hline 33729 & 45.3 & 3.1 & 130.96 & 110 & 210 \\
\hline 34123 & 40 & 4.0 & 19.6 & 200 & 265 \\
\hline 47527 & 55.4 & 3.5 & 18.3 & 150 & 270 \\
\hline 56734 & 50.3 & 3.6 & 12.9 & 130 & 245 \\
\hline 62135 & 35.6 & 1.8 & 99.6 & 140 & 250 \\
\hline 72134 & 55.7 & 2.8 & 99.6 & 140 & 200 \\
\hline 82175 & 30 & 2.8 & 18.2 & 140 & 176 \\
\hline 79639 & 45 & 2.8 & 20.2 & 116 & 200 \\
\hline
\end{tabular}

\section{Table 3: Age of the patient}

\begin{tabular}{ll}
\hline Rural (Years) & No. of patients \\
$30-39$ & 4 \\
$40-49$ & 2 \\
$50-59$ & 9 \\
$60-69$ & 2 \\
$70-79$ & 4 \\
\hline
\end{tabular}

\begin{tabular}{|ll|}
\hline Table 4: Age of the patient at diagnosis of hypothyroidism & \\
\hline Rural (Years) & No. of patients \\
\hline $20-29$ & 5 \\
$30-39$ & 6 \\
$40-49$ & 3 \\
$50-59$ & 5 \\
$60-69$ & 1 \\
\hline
\end{tabular}

shown higher level i.e., $>8$. However, it may be a premature statement to say that control of Type 2 diabetes mellitus may be difficult in hypothyroidism. Large studies involving a greater number of patients followed for a number of years will definitely throw some light into the causation, interrelation, or co-existence of two disorders. ${ }^{[11]}$ As both these disorders require lifelong therapy early recognition and diagnosis definitely help in the prevention and postponement of chronic complications thereby reducing morbidity and mortality. ${ }^{[12]}$ Hence annual screening is mandatory for both hypothyroid 


\begin{tabular}{|ll|}
\hline Table 5: Age of the patient at diagnosis of type 2 diabetes & \\
\hline Rural (Years) & No. of patients \\
\hline $30-39$ & 7 \\
\hline $40-49$ & 3 \\
$50-59$ & 7 \\
$60-69$ & 3 \\
\hline
\end{tabular}

\begin{tabular}{|ll|}
\hline Table 6: Duration (in years) between the diagnosis of hypothyroidism and diabetes \\
\hline Years & No. of patients \\
\hline $0-5$ & 9 \\
$6-9$ & 4 \\
\hline $10-14$ & 3 \\
\hline $15-19$ & 2 \\
\hline $20-24$ & 1 \\
\hline $25-29$ & 1 \\
\hline
\end{tabular}

and diabetic patients, for their coexistence. Further advances in molecular biologic techniques, immunology and human genetics combined with rigorous epidemiological assessments should clarify these observations.

\section{Conclusion}

Hypothyroidism is more commonly seen in female diabetic patients. The onset of Type 2 Diabetes Mellitus in hypothyroid patients is seen within 5 years in the majority of patients. 'Type - II Diabetes Mellituspatients suffering from hypothyroidism may require higher doses of thyroid hormone. Hypothyroidism characterized by raised TSH with normal T3 is noted in $45 \%$ of patients; on the other hand, T4 level normal with TSH raised levels noted in $20 \%$ of patients suggests its subclinical presentation. Hypertension when associated as an added risk factor produces more morbidity. Hyperlipidemia is a common risk factor present in these bihormonal disorders with the increasing incidence of CVA and CAD. Annual Screening is mandatory in all hypothyroid patients for the early detection and treatment of diabetes mellitus, thereby to prevent and/or postpone the complications of diabetes, and all diabetes mellitus patients to undergo thyroid function screening (TFT) yearly for the early detection of thyroid dysfunction and thereby reducing the morbidity and mortality.Further studies are needed to show insight into the association of hypothyroidism and Type-2 Diabetes mellitus.

\section{References}

1. Hage M, Zantout MS, Azar ST. Thyroid Disorders and Diabetes Mellitus. J Thyroid Res. 2011;2011:439463. Available from: https://dx.doi.org/10.4061/2011/439463.
2. Week JH, Hansen. Aa P: Serum thyrotropin-releasing hormone innormal subjects and juvenile diabetics. Diabetologio. 1974;10(2):101-104. Available from: https://doi.org/10.1007/ bf01219664.

3. Joslin EP, Lahey FH. Diabetes and Hyperthyroidism. Am J Med Sci. 1928;176(1):1-22. Available from: https://dx.doi. org/10.1097/00000441-192807000-00001.

4. Kreines K, Jett M, Knowles HC, Jr. Observations in hyperhyoidism of abnormal glucose tolerance and other traits related to diabetes. DM: Diabetes mellitus. 1955;14(11):393393. Available from: https://doi.org/10.2337/diab.14.11.740.

5. Kaveeshwar SA, Cornwall J. The current state of diabetes mellitus in India. Australas Med J. 2014;7(1):45-48. Available from: https://dx.doi.org/10.4066/AMJ.2013.1979.

6. Perros P, McCrimmon RJ, Shaw G, Frier BM. Frequency of Thyroid Dysfunction in Diabetic Patients: Value of Annual Screening; 1995. Available from: https://dx.doi.org/10.1111/ j.1464-5491.1995.tb00553.x.

7. Chakera AJ, Pearce SH, Vaidya B. Treatment for primary hypothyroidism: current approaches and future possibilities. Drug Des Devel Ther. 2012;6:1-11. Available from: https: //dx.doi.org/10.2147/DDDT.S12894.

8. Leng O, Razvi S. Hypothyroidism in the older population. Thyroid Res. 2019;12(2):389-392. Available from: https://doi. org/10.1186/s13044-019-0063-3.

9. Almandoz JP, Gharib H. Hypothyroidism: etiology, diagnosis, and management. Med Clin North Am . 2012;96(2):20321. Available from: https://dx.doi.org/10.1016/j.mcna.2012.01. 005.

10. Khandelwal D, Tandon N. Overt and subclinical hypothyroidism: who to treat and how. Drugs. 2012;72(1):1733. Available from: https://dx.doi.org/10.2165/11598070000000000-00000.

11. Jonklaas J, Bianco AC, Bauer AJ, Burman KD, Cappola AR, Celi FS, et al. Guidelines for the Treatment of Hypothyroidism: Prepared by the American Thyroid Association Task Force on 
Thyroid Hormone Replacement. Thyroid. 2014;24(12):1670 1751. Available from: https://dx.doi.org/10.1089/thy.2014. 0028.

12. Report of the expert committee on the diagnosis and classification of diabetes mellitus. Diabetes care. 1997;20(7):1183-1183. Available from: https://doi.org/10.2337/diacare.20.7.1183.

Copyright: (C) the author(s), 2020. It is an open-access article distributed under the terms of the Creative Commons Attribution License (CC BY 4.0), which permits authors to retain ownership of the copyright for their content, and allow anyone to download, reuse, reprint, modify, distribute and/or copy the content as long as the original authors and source are cited.

How to cite this article: Ajmera P, Sailaja P, Ramulu PR. A Clinical Study of Hypothyroidism Associated With Type - 2 Diabetes Mellitus. Acad. J Med. 2020;3(2):10-15.

DOI: dx.doi.org/10.47008/ajm.2020.3.2.3

Source of Support: Nil, Conflict of Interest: None declared. 